\title{
EFFECTS OF CLAY CONTENT IN SOIL ON PESTICIDES SORPTION PROCESS
}

\author{
SYLVIA V. COPAJA * AND PABLO GATICA-JERIA \\ Departamento de Química, Facultad de Ciencias, Universidad de Chile, Las Palmeras 3425, Nuñoa, Santiago, Chile.
}

\begin{abstract}
Intensive application of pesticides in the agricultural sector and for domestic purposes has resulted in increased usage over the years. Pesticides are used to control pest, diseases and weeds in agricultural and urban areas, but their persistence in the environment has resulted in human poisoning, health risk problem and environmental pollution due to their ability to permeate the soil surface, groundwater systems and water surface bodies.

Sorption of two organophosphorus pesticides: Diazinon and Clorpyriphos was studied in a soil (S) and in soil modified with clay addition. Soil Alhue, VI region, Chile, was spiked with $1 \%$ of either Montmorillonite (M) or Kaolinite (K) (S1). In addition, organic matter (OM), in the soil was eliminated and this soil (S2), was spiked again, with $1 \%$ of both clays. Batch sorption and kinetics experiments were conducted to obtain the retained amounts onto the soil samples. Pesticides were quantified by high performance liquid chromatography (HPLC). The results showed that for both pesticides the sorption order is: S1-M $>$ S1-K $>$ S1. For soil without $\mathrm{OM}$ (S2) the order is the same, although the adsorption was lower. The adsorption isotherms were expressed by the Langmuir and Freundlich models. The negative Gibb's free energy change $\left(\Delta \mathrm{G}^{\circ}\right)$ values obtained suggest that the adsorption of both pesticides, is an exothermic process.

Clay addition to the soil, increased the adsorption processes, generating an increase in the amount of pesticide retained in the soil and partially avoiding possible contamination of the aquifers. The difference found in relation to the behavior of both clays on the soil, can be explained considering its structure and its octanolwater partition coefficient (kow).
\end{abstract}

Keywords: Soils; Diazinon; Chlorpyrifos; clay; sorption constant (Kd); Langmuir and Freundlich models.

\section{INTRODUCTION}

Intensive application of pesticides in the agricultural sector and for domestic purposes has resulted in increased usage over the years. Pesticides are used to control pest, diseases and weeds in agricultural and urban areas, but their persistence in the environment has resulted in human poisoning, health risk problem and environmental pollution due to their ability to permeate the soil surface, groundwater systems and water surface bodies ${ }^{1}$.

When pesticides are introduced into the environment through spraying on crops, droplets of pesticides fall on the soil, plant and water. Hence, it is important to understand the mechanism of interactions than occur between pesticide compound and their behavior in the environment. The fate and mobility of pesticides in the environment involve complex mechanism that are influenced by many processes, including volatilization, leaching, and sorption/desorption, as well as chemical and biological degradation. Of these processes, sorption is the key process in soil because detoxification mechanism, such as degradation, metabolism, microbial uptake and mobilization, involve only the nonsorbed fraction of molecules ${ }^{2-5}$. The extent of sorption depends on various soil properties, including organic matter, amount and type of clay, ion exchange capacity and $\mathrm{pH}$. Moreover, various physical-chemical parameters of these compounds, such as water solubility and octanol-water partition coefficient, also play an important role in determine sorption extent ${ }^{6,7}$.

Pesticide sorption or binding in the soil has been characterized by determining partition of the pesticide between soil and solution resulting in pesticide sorption coefficient $(\mathrm{Kd})^{8,9}$. The soil sorption coefficient, kd, describes the distribution of pesticides between the water phase and soil particles and is one of most important input parameters of mathematical models predicting the fate of pesticides in environments. It has been shown that sorption-desorption capacity of pesticides in soils depend on the type of soil, temperature, $\mathrm{pH}$ and properties of pesticide itself ${ }^{10-12}$. Generally, it has been found that adsorption of pesticides is positively correlated with octanol-water partition coefficient and negatively correlated with their water solubility ${ }^{13}$.

The sorption interaction of pesticide in soil may involve either the mineral or organic components, or both. In soil that have organic matter levels $(>5 \%)$, pesticide adsorption depend on organic matter content, the nature of organic matter having little influence on the on the adsorption processes ${ }^{14-18}$. In soils with low organic matter contents, the adsorption of pesticide often depends on active compounds of the inorganic fraction, which is dominantly the clay fraction. An increase in clay content result increasing adsorption of pesticide ${ }^{4},{ }^{7}$, ${ }^{19-20}$. Sorption-desorption isotherms are usually described by linear models Langmuir and/or Freundlich models.
Organophosphorus pesticides (Ops) are the chemical compounds most used in the world, representing between $30 \%$ and $40 \%$ of insecticide sales in the planet ${ }^{23,22}$. These compounds less persistent than organochlorine pesticides have a higher acute toxicity, with their biocide action affecting a large diversity of organism, and have a low cost, all of which favors their use to control various species that affect food-relevant crops as well as some vectors that represent risks to human health.

Chlorpyrifos and Diazinon pesticides, hydrophobic compounds when applied to soils with a content of organic matter greater than $2 \%$, adsorption occurs mainly due to organic matter acts as a means partition; several authors ${ }^{8,23-24}$, consider that there are limitations to attribute to organic matter as the only responsible for the adsorption of polar compounds. Several authors, working adsorption of organic compounds with polar, ionic or ionizable features, found a higher correlation between adsorption and clay content of soils than with organic matter content. They shows how soil use affects the adsorption of pesticides and their metabolites associated with organic matter ${ }^{25}$.

In this work we propose to study the influence of organic matter and clay addition in the adsorption of Chlorpyrifos and Diazinon in soil, two Organophosphorus pesticides, very used in Chile.

\section{MATERIALS AND METHODS}

\subsection{Soil samples}

Samples of Alhue soil from VI region, General Libertador Bernardo O'Higgins, Chile, was used in this study. Samples of soil $(0-10 \mathrm{~cm})$ were air dried and sieved $(2 \mathrm{~mm})$ before using. The physical and chemical properties of soil were determined by described methods ${ }^{27}$.

\subsection{Reagents and material}

The pesticides chosen for this study were Chlorpyrifos and Diazinon both pesticides were purchased from Aldrich Chemical Company Inc. whit reported purity $>98 \%$. Stock solutions $100 \mathrm{mgL}^{-1}$ of each pesticide standard was prepared by dissolving the weighed in acetonitrile (Merck HPLC grade). Working standard mixed solutions were prepared weakly by diluting each individual stock solution with acetonitrile and storing at $4{ }^{\circ} \mathrm{C}$. All reagents used were of analytical grade, like acetonitrile, Calcium Chloride $\left(\mathrm{CaCl}_{2}\right)$, Chlorhydric acid $(\mathrm{HCl})$, Hydrogen Peroxide $\left(\mathrm{H}_{2} \mathrm{O}_{2}\right)$, were procures from Merck (Darmstadt, Germany). Purifies water was prepared using a Milli-Q purification system (Simplicity) for HPLC analysis. Clays used were Kaolinite $\left(\mathrm{Al}_{2} \mathrm{O}_{3} \cdot 2 \mathrm{SiO}_{2} \cdot 2 \mathrm{H}_{2} \mathrm{O}\right)$ and Montmorillonite $10 \mathrm{~K}\left(\mathrm{SiO}_{2} / \mathrm{Al}_{2} \mathrm{O}_{3}\right)$ (Sigma-Aldrich). The pesticides studied and some of their physical-chemical properties are presented in table 1. 
Table 1: Selected properties of pesticides investigated ${ }^{28 .}$

\begin{tabular}{|c|c|c|c|c|c|}
\hline Pesticides & chemical structure & $\begin{array}{l}\text { molecular weight } \\
\left(\mathrm{g} \cdot \mathrm{mol}^{-1}\right)\end{array}$ & $\log$ Kow & $\begin{array}{c}\text { solubility in water } \\
\left(\mathrm{mgL}^{-1}\right)\end{array}$ & $\begin{array}{c}\text { Vapor preasure } \\
(\mathrm{mm} \mathrm{Hg})\end{array}$ \\
\hline Diazinon & & 304.35 & 3.69 & 60 & $9.0 \times 10^{-6}$ \\
\hline Clorpiryfos & & 350.59 & 4.70 & 1.05 & $1.0 \times 10^{-5}$ \\
\hline
\end{tabular}

\subsection{Samples of soil preparation}

\subsubsection{Elimination of organic matter}

The organic matter was removed from the soil by oxidation with $\mathrm{H}_{2} \mathrm{O}_{2}$. For this, soil samples of $20 \pm 0.01 \mathrm{~g}$ were taken in $250 \mathrm{~mL}$ Erlenmeyer flasks, 100 $\mathrm{mL}$ of water was added and then $40 \mathrm{~mL} 1 \mathrm{~N} \mathrm{HCL}$. It was stirred and the solution was heated. Then, was added $10 \mathrm{~mL}$ of $30 \% \mathrm{H}_{2} \mathrm{O}_{2}$, and was digested with careful heating. Finally, $5 \mathrm{~mL}$ of $\mathrm{H}_{2} \mathrm{O}_{2}$ is added to complete the digestion. The suspension was centrifuged, the supernatant was separated and the soil was allowed to dry in Petri dishes. The absence of carbon in the dry sample was checked by Walkley and Black method ${ }^{27}$.

\subsubsection{Clay addition}

To soil samples with $\mathrm{MO}$ (S1) and without MO (S2), kaolinite and Montmorillonite clays were added according to the following scheme:

$$
\begin{array}{ll}
\text { S1K } & 99.00 \mathrm{~g} \pm 0.01 \mathrm{~g}+1.00 \mathrm{~g} \pm 0.01 \mathrm{~g} \text { of Kaolinite } \\
\mathrm{S} 1 \mathrm{M} & 99.00 \mathrm{~g} \pm 0.01 \mathrm{~g}+1.00 \mathrm{~g} \pm 0.01 \mathrm{~g} \text { of Montmorillonite } \\
\mathrm{S} 2 \mathrm{~K} & 99.00 \mathrm{~g} \pm 0.01 \mathrm{~g}+1.00 \mathrm{~g} \pm 0.01 \mathrm{~g} \text { of Kaolinite } \\
\text { S2M } & 99.00 \mathrm{~g} \pm 0.01 \mathrm{~g}+1.00 \mathrm{~g} \pm 0.01 \mathrm{~g} \text { of Montmorillonite }
\end{array}
$$

\subsection{Determination of contact time.}

The time in which the pesticide is applied to the soil reaches equilibrium between the different phases, that is, the time at which the concentrations of pesticide adsorbed to soil or dissolved in the solution remains constant. This step is necessary to validate the subsequent adsorption isotherm studies in which is required a periods of continuous stirring of set soil-pesticide, which must be greater than time needed to reach equilibrium. For this purpose 1 gram of each soil type was weighed separately in $20 \mathrm{~mL}$ conical centrifuge bottles containing $10 \mathrm{~mL}$ of each pesticide solution $100 \mathrm{mgL}^{-1}$. The mixtures were shaken on a horizontal orbital shaker at $100 \mathrm{rpm}$ time intervals were $3,6,12,24,48$, and 72 hours. Next, the suspensions were centrifuged at $3500 \mathrm{rpm}$ for $15 \mathrm{~min}$ and the supernatant sieved $0.22 \mu \mathrm{m}$ filter (PVDF) in a syringe filter $(1.5 \mathrm{~mL})$ before injected into HPLC for its quantification.

\subsection{Adsorption Isotherms}

Once the equilibrium time was determined, the adsorption process was studied through experiments in Batch. Adsorption of pesticides in soil was performed by weighing $1.0 \mathrm{~g}$ of each soil type: S1; S2; S1K; S1M; S2K; S2M. A set of 11 polyethylene bottles was prepared, to which $1.000 \pm 0.001 \mathrm{~g}$ of the different soil samples, then was added $10 \mathrm{~mL}$ of $0.01 \mathrm{M} \mathrm{CaCl}_{2}$ solution and zero of the pesticide solutions, labeled as bottle 1 , up to $0 \mathrm{~mL}$ of $0.01 \mathrm{M} \mathrm{CaCl}_{2}$ and $10 \mathrm{~mL}$ of the pesticides labeled as bottle 11. Samples were stirred at $100 \mathrm{rpm}$ with an orbital shaker, during 48 hours, time determined previously. After stirring, the entire supernatant was transferred to $15 \mathrm{~mL}$ centrifuge tubes, which were centrifuged at $3500 \mathrm{rpm}$ for $15 \mathrm{~min}$. After time, the supernatant is filtered with $0.22 \mu \mathrm{m}$ pore PVDF filters and stored refrigerated for further HPLC analysis. The study was done in duplicate.

\subsection{Chemical analysis.}

The determination of Chlorpyrifos and Diazinon was carried out with the help of a high performance liquid chromatography device with diode array detector (HPLC - PDA) WATERS 1525 BINARY HPLC Pump. Column: Atlantis $\mathrm{C}_{18}$, $5.0 \mu \mathrm{m}$ (Waters); Detector: Photodiode Arrangement, PDA (Waters 2996); Injection volume: $20 \mu \mathrm{L}$; flow $1.0 \mathrm{~mL} / \mathrm{min}$.

Compositions of mobile phases for the different compounds:

- Chlorpyrifos: Acetonitrile / water $\mathrm{pH}=3.0\left(\mathrm{H}_{3} \mathrm{PO}_{4}\right) 80 / 20 \mathrm{v} / \mathrm{v}$; Injection volume: $20 \mu \mathrm{L}, \lambda=220 \mathrm{~nm}$;

- Diazinon: Acetonitrile / water / 70/30 v / v; Injection volume: $20 \mu \mathrm{L}, \lambda=$ $232 \mathrm{~nm}$.

\subsection{Data processing}

\subsubsection{Elovich model}

This process allows determining the amount of adsorbate that is recovered in a set time ${ }^{29}$. To apply the model, the adsorbed concentration (Cs exp.) is plotted as a function of $\operatorname{Ln}$ of the stirring time $(\operatorname{Ln}(t))$, from which a logarithmic equation (equation 5) is applied from which the value of Cs.

$$
\mathrm{Cs}=1 / \mathrm{b} \operatorname{Ln}(\mathrm{ab})+1 / \mathrm{b} \operatorname{Ln}(\mathrm{t})
$$

Through this model it is possible to establish whether the experimental and theoretical data obtained have a correlation. To determine if the adjustment made by the kinetic model is good, analyze two experimental parameters: $\mathrm{R}^{2}>0.8$ and relative error $(\mathrm{RE})<10 \%$,

\subsubsection{Adsorption parameters}

Soil sorption was characterized by the partition constant $(\mathrm{kd}) \mathrm{mL} / \mu \mathrm{g}){ }^{30,31}$. The adsorption coefficient $(\mathrm{kd})$ was defines by Equation 2 .

$$
\mathrm{kd}=\mathrm{Cs} / \mathrm{Ce}
$$

The linear or distribution coefficient $(\mathrm{Kd})$ is related to soil organic carbon $(\mathrm{OC})$ and soil organic matter (OM) by the following equations ${ }^{32,33}$.

$$
\begin{aligned}
& \% \mathrm{OC}=\% \mathrm{OM} / 1.724 \\
& \mathrm{KOM}=100 \times \mathrm{Kd} /(\% \mathrm{OC}) \\
& \mathrm{KOC}=100 \mathrm{Kd} /(\% \mathrm{OC})
\end{aligned}
$$

\subsubsection{Gibbs or free energy change}

The standard Gibbs or free energy change of adsorption $(\Delta G)$ from the Freundlich isotherm can be calculated using the following relation ${ }^{32,33}$.
$\Delta \mathrm{G}=-\mathrm{RTLnK}_{\mathrm{OM}}$
(eq. 6)

Where, $R$ is the gas constant $\left(8.31 \mathrm{~J} \mathrm{~K}^{-1} \mathrm{~mol}^{-1}\right)$, and $T$ is the Kelvin temperature (303 K). 


\subsubsection{Adsorption models}

- Langmuir model.

This model can be applied to pesticides in soils, and determines the saturation of the available sites ${ }^{34}$.

The expression for the model is given by the following equation:

$$
\mathrm{Qo}=\mathrm{Ce} /(\mathrm{Cs})=1 / \mathrm{bX}+\mathrm{Ce} / \mathrm{X}_{\mathrm{m}} \quad \text { (eq. 7) }
$$

Where, Cs $\left(\mathrm{mgg}^{-1}\right)$ is the amount of pesticide adsorbed per unit mass of adsorbent, $\mathrm{Ce}\left(\mathrm{mgL}^{-1}\right)$ is the equilibrium solution concentration, $\mathrm{Xm}$ is the adsorption capacity and $\mathrm{b}$ is a constant related to the energy of link between adsorbent and adsorbate ${ }^{35}$.

The Langmuir parameter $\left(\mathrm{R}_{\mathrm{L}}\right)$, calculated through the affinity constant $(b)$, is also called: "equilibrium parameter" or "separation factor", where depending on the value of $R_{L}$, the equation is as follows:

$$
R_{L}=\frac{1}{(1+b)}
$$

$\mathrm{C}=10 \mathrm{mgL}^{-1}$, maximum adsorption concentration and $\mathrm{b}$ is the binding energy associated with adsorbent and adsorbate. Adsorption can be classified as: irreversible, if $\mathrm{R}_{\mathrm{L}}=0$; favorable, if $0<\mathrm{R}_{\mathrm{L}}<1$; linear, if $\mathrm{R}_{\mathrm{L}}=1$; unfavorable, if $\mathrm{R}_{\mathrm{L}}>1^{36}$.

\section{- Freundlich model.}

The pesticide concentration in the soil and soil solutions were fitted to the linearized Freundlich sorption isotherm Equation (9).

$$
\ln \mathrm{Cs}=\ln \mathrm{kd}+1 / \mathrm{n} \ln \mathrm{Ce} \quad \text { (eq. 9) }
$$

Where $\mathrm{Cs}$ in the concentration of pesticide adsorbed in soil $\left(\mathrm{mgkg}^{-1}\right), \mathrm{Ce}$ is the concentration of pesticide in soil solution $\left(\mathrm{mgmL}^{-1}\right)$; and $\mathrm{kd}$ are constant. The value $1 / \mathrm{n}$ is the energy distributions of the adsorption site ${ }^{37}$.

\section{RESULTS AND DISCUSSIONS}

The main physical-chemical properties of the soil are given in table 2

Table 2. Physicochemical properties of soil Alhue.

\begin{tabular}{|c|c|c|c|c|c|c|}
\hline $\mathbf{p H}$ & $\mathbf{C E}[\mathbf{d S} / \mathbf{m}]$ & $\mathbf{C O}(\%)$ & CIC $(\mathbf{c m o l} / \mathbf{k g})$ & \multicolumn{3}{|c|}{ Texture (\%) } \\
\hline & & & & Sand & Silt & clay \\
\hline $6.36 \pm 0.14$ & $0.13 \pm 0.01$ & $1.98 \pm 0.04$ & $6.27 \pm 0.08$ & 76.77 & 22.19 & 1.56 \\
\hline
\end{tabular}

The texture of soil was classified as sandy. The soil was acid to neutral with $\mathrm{pH}$ 6.36. The OC content and CIC are lower in relation with others agricultural soils.

\subsection{Equilibrium time.}

The equilibrium time for the two pesticides in soil with clays addition are shown in the next figures.

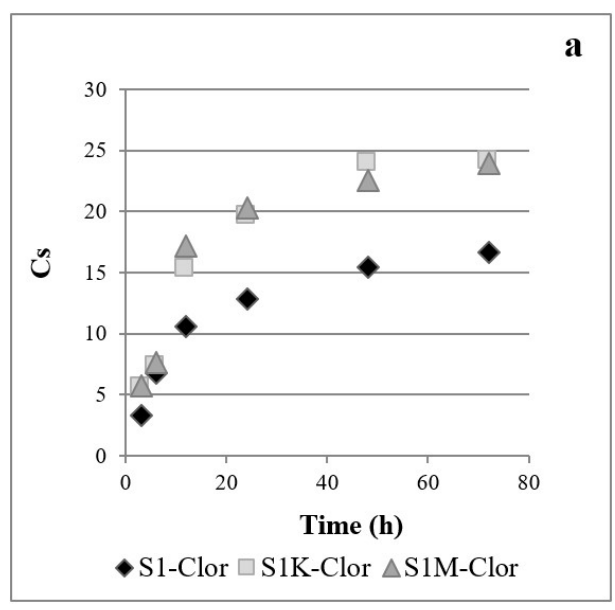

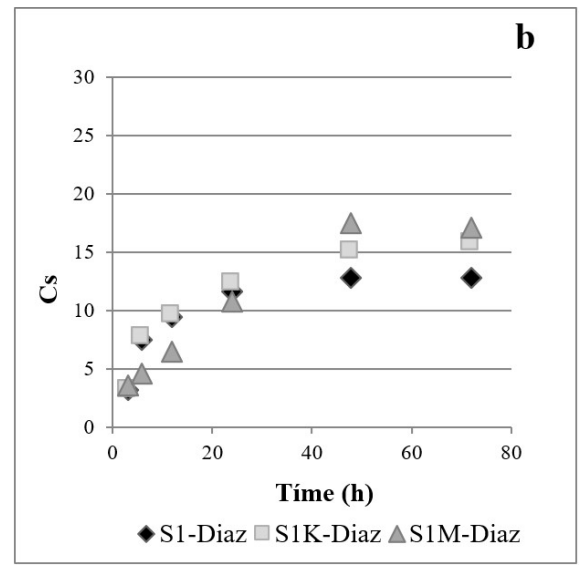

Figure 1. Pesticides concentration adsorbed by soil and soil modified with clays at different time intervals, a) Clorpyriphos; b) Diazinon.

Figure 1 shows the concentration of both pesticides adsorbed by the soil at different time intervals. The adsorption equilibrium times of both pesticides in the soil were characterized by an initial rapid adsorption, which eventually reached a constant, and this could be due to the limited surface area on the soil particles for pesticides adsorption. The adsorption kinetics exhibited two distinct stages, a very rapid adsorption at the initial stages (within 10 hours, Clorpyriphos > Diazinon), followed by slow adsorption. After 30 hours shaking in the soil, the adsorption of Diazinon and Clorpyriphos became very slow and reached a constant after achieving equilibrium between the soil matrix and solution.

\subsection{Elovich model}

There are several models to determine the kinetic adsorption process; one of them is the Elovich kinetic model that is applied to heterogeneous solid-liquid adsorption systems. This model is suitable for general applications that have chemistry kinetics.

To determine if the adjustment made by the kinetic model is good, analyze two experimental parameters: $\mathrm{R}^{2}>0.8$ and relative error (RE) $<10 \%$, which difference between experimental values and those obtained from the model, that is, difference of the measured value and the theoretical value divided by the exact value $^{38}$. The correlation values obtained by applying equation 1 and the relative error values (RE) are shown below (eq. 1).

Table 3. Values of ARE (relative error) and $\mathrm{R}^{2}$ (correlation coefficient) for Chlorpyrifos and Diazinon in soil and soil modified with clays.

\begin{tabular}{|c|c|c|}
\hline Soil samples & ARE (\%) & $\mathbf{R}^{\mathbf{2}}$ \\
\hline S1-Clor & 3.9 & 0.98 \\
\hline S1K-Clor & 1.9 & 0.94 \\
\hline S1M-Clor & 2.1 & 0.97 \\
\hline S1-Diaz & 3.5 & 0.99 \\
\hline S1K-Diaz & 3.8 & 0.99 \\
\hline S1M-Diaz & 2.7 & $\mathbf{0 . 7 9}$ \\
\hline
\end{tabular}

In general, looking at table 3, a good fit of the model is found for all the systems under study, except for Diazinon with Montmorillonite (S1M-Diaz) $\left(\mathrm{R}^{2}=0.79\right)$.

\subsection{Sorption isotherms}

Sorption of pesticides is generally evaluated by the use of sorption isotherms $19,{ }^{39-41}$. Batch equilibrium is a common technique used to determine soil sorption of pesticides. In a batch equilibrium technique, a series of solutions containing the pesticide to be tested at different concentrations are prepared. The solutions are then mixed with known amount soil and shaken until equilibrium is achieved. The concentration of the chemical in the solutions is then measured and a difference in the mass of the pesticide between at the start and at equilibrium is assumed to be due to adsorption by the soil particles. 
Then, the amount of pesticide adsorbed per unit weight of soil is calculated for each initial concentration of the pesticide ( $\mathrm{Ca}$ - $\mathrm{Ce}$ ). A relationship is then established between the pesticide concentration at equilibrium and the adsorbed concentration of the pesticide by the soil ${ }^{42}$. A sorption isotherm shows a relationship between the amounts of pesticide adsorbed per unit weight of the soil (Cs) and the pesticide concentration in the solution at equilibrium (Ce).

The empirical classifications of sorption isotherms are divided into four main classes according to shape of the sorption isotherm. The S-type isotherms are common when the solid has a high affinity for the solvent.
The initial direction of curvature in the S-type isotherm indicates that adsorption becomes easier as concentration increases. The L-type isotherm represents a relatively high affinity between the solid and solute in the initial stages of the isotherm. As more sites in the substrate are filled, it becomes increasingly difficult for the pesticide to find available sites for sorption to take place. The C-type isotherm is depicted by a pesticide that penetrates into the soil more readily than water molecules. The H-type isotherm is quite uncommon and occurs only when there is a very high affinity between a pesticide and the soil ${ }^{43}$.

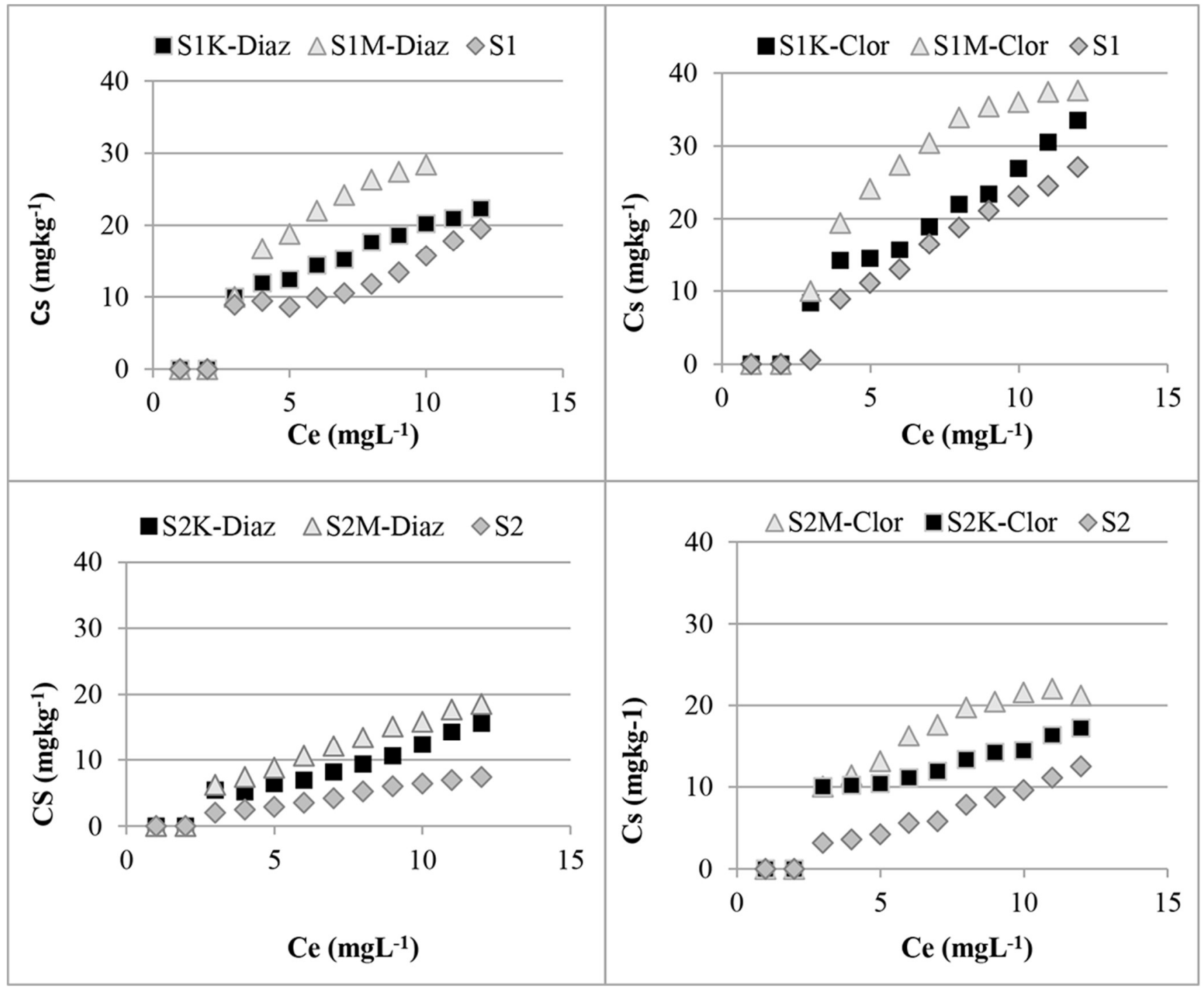

Figure 2. Adsorption isotherms in soils and soils modified with clays, with OC (S1) and without OC (S2).

Given the shape and curvature of the isotherms are classified as type $\mathrm{C}$ isotherms, characterized by a constant contribution of the affinity between pesticides and soil functional groups present in the soil organic matter for S1MClor, S2M-Clor, S1M-Diaz and S2M-Diaz. Although a slight tendency to type S isotherm is observed for the case of the S1-Clor, S2-Clor, S1K-Clor, S2K-Clor, S2-Diaz, S1K-Diaz and S2K-Diaz, indicating that the adsorption between the pesticide, water and previously adsorbed molecules is relevant in this process.

Looking at Figure 2, it is possible to infer that for Chlorpyrifos the adsorption order is on the soil with organic matter (S1) is: S1M-Clor $>$ S1KClor $>$ S1Clor. In the case of soil without organic matter (S2), the order of adsorption is the same only that the concentration of the adsorbed compound is lower; clearly showing the clay influences this process, although the interaction of the pesticide with the organic matter is also important. In the same way it is possible to observe the same behavior with Diazinon in the soil with organic matter but the adsorption is lower.
The most frequently used isotherms for pesticides sorption are the Freundlich, Langmuir, and linear isotherms ${ }^{44,45}$.

\subsubsection{Langmuir Model.}

The Langmuir isotherm model corresponds to a monolayer adsorption. The adsorbed amount increases until a limit value corresponding to the surface coating by a monolayer is reached. The Langmuir adsorption equation was initially derived from the adsorption of gases by solids using the following assumptions: (i) the energy of adsorptions is constant and independent of surface charge; (ii) adsorption is on localized sites and there is no interaction between adsorbate molecules; and (iii) the maximum adsorption occurs as a complete monolayer.

The following table shows the Langmuir parameters for the Chlorpyrifos and Diazinon adsorption process (eq. 4). 
Table 4. Langmuir parameters for Clorpyriphos and Diazinon in soil samples.

\begin{tabular}{|c|c|c|c|c|}
\hline Soil samples & $\mathbf{Q}_{\mathbf{0}} \mathbf{m g g}^{-\mathbf{1}} \mathbf{)}$ & $\mathbf{b}\left(\mathbf{m g L}^{\mathbf{- 1}}\right)$ & $\mathbf{R}_{\mathbf{L}}$ & $\mathbf{R}^{\mathbf{2}}$ \\
\hline S1-Clor & 0.16 & 0.40 & 0.20 & 0.98 \\
\hline S1K-Clor & 0.12 & 0.27 & 0.27 & 0.97 \\
\hline S1M-Clor & 0.05 & 0.25 & 0.29 & 0.99 \\
\hline S2-Clor & 0.39 & 0.24 & 0.07 & 0.95 \\
\hline S2K-Clor & 0.10 & 0.55 & 0.06 & 0.99 \\
\hline S2M-Clor & 0.10 & 0.61 & 0.14 & 0.96 \\
\hline S1-Diaz & 0.11 & 0.61 & 0.06 & 0.99 \\
\hline S1K-Diaz & 0.09 & 0.84 & 0.11 & 0.98 \\
\hline S1M-Diaz & 0.06 & 0.44 & 0.19 & 0.99 \\
\hline S2-Diaz & 0.38 & 0.09 & 0.03 & 0.95 \\
\hline S2K-Diaz & 0.20 & 0.31 & 0.07 & 0.98 \\
\hline S2M-Diaz & 0.18 & 0.70 & 0.12 & 0.99 \\
\hline
\end{tabular}

According to Table 4, all $\mathrm{R}_{\mathrm{L}}$ values would adjust to a favorable adsorption, having an $\mathrm{R}^{2}>0.95$ (eq. 5). In addition, the maximum adsorption capacity parameter (Qo) can be observed ${ }^{46}$, which is related to the area occupied by a mono molecular layer of adsorbate. In this case, for Chlorpyrifos, it is observed that $\mathrm{Q}_{0}$ is $\mathrm{S} 1 \mathrm{M}$-Clor $<\mathrm{S} 1 \mathrm{~K}$-Clor $<\mathrm{S} 1$-Clor. Therefore, it is inferred that the area of the mono molecular layer is smaller as the clay is added; this is because when the clay is added to the soil, it changes its mechanism of adsorption, which could best be described with another kinetic model. The same effect occurs by eliminating organic matter from the soil.

For Diazinon, according to table 2, there is a favorable adsorption for all cases, because the Langmuir $\mathrm{R}_{\mathrm{L}}$ parameter varies between $0-1$, where all cases have an $\mathrm{R}^{2}$ greater than or equal to 0.95 . In the same way it is possible to observe the same behavior as Chlorpyrifos, whereas the clays are added the area of the mono molecular layer decreases, obtaining: $\mathrm{Q}_{0}$ is $\mathrm{S} 1 \mathrm{M}-\mathrm{Diaz}<\mathrm{S} 1 \mathrm{~K}-\mathrm{Diaz}<\mathrm{S} 1$-Diaz, both for soil and soil without MO.

\subsubsection{Freundlich model}

The empirically derived Freundlich equation has been used to describe the adsorption of pesticides by soil, organic matter and clay minerals ${ }^{41}$. One way to analyze the application of the Freundlich model is through the adsorption intensity constant $\left(\mathrm{n}_{\mathrm{f}}\right)$ and the adsorption capacity constant $\left(\mathrm{K}_{\mathrm{f}}\right)$, parameters that correspond to the slope and the intercept of the straight line equation respectively. If $\mathrm{n}_{\mathrm{f}}>1$, the adsorption is considered favorable ${ }^{47}$, and if $\mathrm{R}^{2}$ is greater than 0.95 according to the linearized equation. The Freundlich constant $\mathrm{K}_{\mathrm{f}}$ determines the adsorbate-adsorbent affinity, in which the higher $\mathrm{Kf}$ the greater the affinity ${ }^{48}$ (eq. 6).

The Freundlich model applied to Chlorpyrifos and Diazinon with and without $\mathrm{OC}$ is shown below.

Table 5. Freundlich parameters for Clorpyriphos and Diazinon in soil samples.

\begin{tabular}{|c|c|c|c|}
\hline Soils & $\mathbf{K}_{\mathbf{f}}$ & $\mathbf{n f}$ & $\mathbf{R}^{\mathbf{2}}$ \\
\hline S1-Clor & 7.29 & 0.51 & 0.99 \\
\hline S1K-Clor & 11.4 & 0.83 & 0.95 \\
\hline S1M-Clor & 26.8 & 0.97 & 0.95 \\
\hline S2-Clor & 2.22 & 0.31 & 0.98 \\
\hline S2K-Clor & 7.87 & 0.87 & 0.95 \\
\hline S2M-Clor & 11.9 & 0.10 & 0.92 \\
\hline S1-Diaz & 5.06 & 0.69 & 0.89 \\
\hline S1K-Diaz & 9.79 & 0.52 & 0.99 \\
\hline S1M-Diaz & 18.9 & 0.06 & 0.98 \\
\hline S2-Diaz & 1.52 & 0.41 & 0.98 \\
\hline S2K-Diaz & 3.58 & 0.55 & 0.95 \\
\hline S2M-Diaz & 6.20 & 0.96 & 0.99 \\
\hline
\end{tabular}

As observed in Table 5, the values that can be explained by the Freundlich model, except S2M-Clor and S1-Diaz with $\mathrm{R}^{2}<0.95$. All other results fit this model. Adsorption intensity $\mathrm{n}_{\mathrm{f}}$, turned out to be favorable for all the cases they adjusted, because they are values $>1$. It should be noted that when adding Kaolinite and Montmorillonite to the soil, the adsorption intensity is greater.

With regard to the adsorption capacity constant $\mathrm{K}_{\mathrm{f}}$, the results obtained for soil are greater than for those of soil without OC (S2), that is, the pesticide would be more strongly retained by having organic matter. This parameter is also increased when the clays are added, from which it can be inferred that the adsorption capacity of the soil increases.

Long Yu et al. (2005) ${ }^{49}$, conclude that the behavior of Chlorpyrifos in the adsorption processes is controlled by the content of OC and its octanol/water partition coefficient. These compounds may form hydrogen bonds with soil humic substances and sulfur, oxygen and nitrogen, latter atoms favors a high coefficient (close to 1) in the intensity of Diazinon adsorption, gives larger size and a high electron affinity that does not allow to determine at tendency to about the adsorption intensity coefficient. This also indicates that the Chlorpyrifos pesticide will have less intensity to penetrate the reactive sites of the organic matter, while for Diazinon be facilitated.

\subsubsection{Kd and Koc parameters}

The distribution coefficients $(\mathrm{Kd})$ and adsorption (Koc) provide information regarding the interaction between adsorbate and adsorbent. The distribution coefficient $(\mathrm{Kd})$ represents the mobility of compounds in soils, indicating the ability of the soil to retain a compound. On the other hand, the adsorption coefficient (Koc) indicates a greater or lesser affinity of the pesticides with the organic fraction of the soil; a high Koc indicates that the pesticide is firmly fixed in the matter organic soil, so a small amount of the compound could be mobilized to surface waters or aquifers. The values obtained are shown in the following table: (eq. 2; eq. 3 ).

Table 6. Kd and Koc parameters for Chlorpyrifos and Diazinon in soil samples.

\begin{tabular}{|c|c|c|}
\hline Soil samples & Kd & Koc \\
\hline S1-Clor & 4.93 & 249 \\
\hline S1K-Clor & 6.08 & 370 \\
\hline S1M-Clor & 15.61 & 788 \\
\hline S2-Clor & 1.31 & - \\
\hline S2K-Clor & 3.11 & - \\
\hline S2M-Clor & 5.43 & 134 \\
\hline S1-Diaz & 2.66 & 283 \\
\hline S1K-Diaz & 5.60 & 474 \\
\hline S1M-Diaz & 9.38 & - \\
\hline S2-Diaz & 0.92 & \\
\hline
\end{tabular}

$\mathrm{Kd}$ for all studied soil samples were ranged from 4.93 to 15.61 for Clorpyrifos, while Kd for Diazinon ranged from 2.66 to 9.38. For both pesticides Koc ranged from 1.34 to 788 signifying that Clorpyriphos and Diazinon has little to no leaching potential which is depending on soil type ${ }^{33,50}$. Usually values of Koc and Kom below 500 specify minimum or no adsorption at all of a pesticide to the soil indicate high probability of runoff or leaching. Pesticides have been categorized into three classes based on Koc by Shan et. al i.e. very high mobility group having koc values less than 50 , high to medium mobility group having Koc values 150 to 500 and low mobility group having Koc values more than 500 ${ }^{33}$. Values of these two parameters strongly dependents on nature and properties of soil.

In relation to the value of $\mathrm{Kd}$, both for the interaction of Chlorpyrifos and Diazinon with both clays, the same order is found in the soil with and without organic matter, that is, S1M Clor or Diaz $>\mathrm{S} 1 \mathrm{~K}$ will be retained better in soils, because it is much more lipophilic than Diazinon. 
Therefore, for Chlorpyrifos and Diazinon, both pesticides are adsorbed even though the organic matter has been removed from the soil. And when adding clay minerals, both to soil and soil without organic matter, it can also be seen that there is an increase in the amount of pesticide adsorbed. In relation to the constant koc, a similar behavior is observed, in addition of Montmorillonite favors the adsorption process S1- Clor or Diaz $>$ S2-Clor or Diaz. The difference observed in the behavior of both clays, could be explained, because Diazinon has a Kow less than Chlorpyrifos $(\log ($ Kow $)$ Diazinon $=3.7<\log ($ Kow $)$ Chlorpyrifos $=$ 4.7). That is, since the Kow is lower, it is inferred that Chlorpyrifos.

Koc determined for Chlorpyrifos and Diazinon in andic soils were recordec between $8444-9943$ and $5800-6300$ respectively ${ }^{51}$, literature values of 6070 to 1000 for Chlorpyrifos and Diazinon soil with organic matter not greater than $2 \%$ are reported, The high absorption coefficient with both pesticides in andic soils is highlighted and high values of Koc registered representing a high $\mathrm{Kd}$ and therefore such a high concentration of pesticides adsorbed to the soil as reported in soils ${ }^{52}$ with high organic matter content. This makes us think that our experimental values are not in agree with the values reported and given the specific characteristics of these soils. This can explain the composition given by extracts of organic matter in different state of humification on profile at different depths, high level of transformation of organic matter and environmental equilibrium conditions, physical and chemical of the area, which makes it work as a retainer, regulator and debugger all types of organic and inorganic compounds arriving there by natural phenomena or human activities

\subsubsection{Gibbs free energy change}

In the next table is show the free energy change values of soil samples

Table 7. $\Delta \mathrm{G}^{\circ}$ values for Chlorpyrifos and Diazinon in soil samples.

\begin{tabular}{|c|c|c|}
\hline Soil samples & $\boldsymbol{\Delta G}^{\circ}$ & Koc \\
\hline S1-Clor & -4.93 & 249 \\
\hline S1K-Clor & -6.08 & 370 \\
\hline S1M-Clor & -15.61 & 788 \\
\hline S1-Diaz & -2.66 & 134 \\
\hline S1K-Diaz & -5.60 & 283 \\
\hline S1M-Diaz & -9.38 & 474 \\
\hline
\end{tabular}

The negative $\Delta \mathrm{G}^{\circ}$ (Gibbs free energy change) values obtained in the present study indicate that the adsorption of Clorpyriphos and Diazinon onto soil samples is a spontaneous process and that the adsorption was an exothermic process. The negative $\Delta \mathrm{G}^{\circ}$ values indicate that the $\mathrm{H}$ bonds were the main interaction in the adsorption process in the soil ${ }^{12}$.

Organic pesticides can generally be classified as cationic, anionic, or nonionic. Particularly, in the case of Chlorpyrifos and Diazinon, both pesticides belong to the category of non-ionic ${ }^{53}$.

Generally, the interactions between pesticides and clays are by ion exchange or the difference in polarity between atoms of metallic origin and pesticides ${ }^{54}$. Therefore, the interactions with the inner layers of the $2: 1$ clays, as is the case of Montmorillonite, with which there is a considerable increase in the adsorption of pesticides with respect to the soil alone, will be a direct coordination with the nitrogen atom contained in the rings of both organophosphorus pesticides, with the $\mathrm{Mg}^{+2}$ atom of clay ${ }^{55,56}$. This coordination is given by a dipole induced by the $\mathrm{Mg}^{+2}$ atoms to the nitrogen heteroatoms found in the rings.

The mechanism of pesticides with Montmorillonite clay would be of the dipole-induced dipole type. ${ }^{57-59}$. For Kaolinite, it has a similar effect, because it has the octahedral alumina layer ${ }^{60,61}$ on one of the faces, where aluminum atoms $\left(\mathrm{Al}^{+3}\right)$ induce a dipole-induced dipole effect just like Montmorillonite. ${ }^{62-64}$.

\section{CONCLUSIONS}

A study of adsorption of two organophosphorus pesticides, Clorpyriphos and Diazinon in a soil Alhué VI region of Chile, modified with $1 \%$ of Kaolinite or Montmorillonite was conducted.
Adsorption of Chlorpyrifos and Diazinon pesticides in this type of soil occurs in maximum after 30 hours due to the low concentration of organic matter.

Of the two isotherm models applied, Langmuir and Freundlich, for both isotherm was found to best fit the experimental data as indicating from the high values of the correlation coefficients $\left(\mathrm{R}^{2}\right)$.

Based on values of $\mathrm{Kd}$ and Koc estimated, all the pesticides have low absorptivity in the soil samples and therefore, will probably display a high mobility.

Clay addition to the soil, increased the adsorption processes, generating an increase in the amount of pesticide retained in the soil and partially avoiding possible contamination of the aquifers.

The elimination of organic matter from the soil demonstrated its importance in the adsorption process, since even when adsorption occurs due to the presence of clays, it decreases markedly.

With the objective of assessing the environmental risk of such compounds and their residues, further studies should be conducted to evaluate their toxicological effects on soil organisms in similar soil conditions.

\section{ACKNOWLEDGMENTS}

This work has been financially by Departamento de Química. Facultad de Ciencias. Universidad de Chile.

\section{CONFLICT OF INTEREST}

The authors declare that they have no conflict of interest.

\section{REFERENCES}

1. K. Rama Krisna, L. Philip, Journal of Hazardous Materials. 160, 559, (2008).

2. P. M. Huang, R. B. McKercher, Soil Science. 138, 20, (1984).

3. G. J. Welhouse, W. F. Bleam, Environ. Sci. Technol. 26, 959, (1992b).

4. G. J. Welhouse, W. F. Bleam, Environmental Science \& Technology. 27, 594, (1993a).

5. J. Pignatelo, B. Xing, Environmental Science of Technology. 30, 1, (1996)

6. G. Singh, W. F. Spencer, M. M.Cliatb, M. Th. Van Genubten, Journal of Environmental Quality. 19, 520, (1990).

7. E. Barriuso, U. Baer, R. Calvet, Journal of Environmental Quality, 21, 359 , (1992).

8. R. D. Wauchope, J.B.H. Yeh, R. Lindres, K. Kloskowski, B. Tanaka, J. Rubin, Pesticide Management Science. 58, 419, (2002).

9. T. Berglof, W. C.. koskinen, M. J. Duffy, k. A. Norberg, H. Kylin, Journal of Agricultural and Food Chemistry. 51, 3598, (2003).

10. B. S. Ismail, K.E. Ooi, Journal of Environmental Biology. 33, 573, (2012).

11. J. H. Cao, H. M. Guo, L. Zhu, H. Jiang, H. Yang, Chemosphere. 70, 2127, (2008)

12. X. Li, Q. Zhou, S. Wei, W. Ren, X. Sun, Geoderma. 160, 347, (2011).

13. N. Singh, Journal of Agricultural and Food Chemistry. 50, 6434, (2002).

14. G. W. Bailey, J. L. White, Journal of Agricultural and Food Chemistry. 2 , 324, (1964).

15. M. H. B. Hayer, Residue Review. 32, 131, (1970).

16. M. Arienzo, A. Buondonno, Toxicological \& Environmental Chemistry 39, 193, (1993).

17. B. M. Jenks, F. W. Roeth, A. D. Martin, D. L. Mccallister, Weed Science. 46, 132, (1998).

18. M. Beckbolet, O. Yernigun, T. Yucel, Water air soil Pollut. 111, 75, (1999).

19. E. M. Murphy, J. M. Zachara, S. C. Smith, J. L. Phillips, Science and Total Environment. 1, 17-118, 413, (1992).

20. S. Baskaran, N. S. Bolan, A. Rahman, R. W. Tillman, J. Agric. Res. 39, 297 , (1996).

21. B. Singh, A. Walker, Microbiol. Rev. 30, 428, (2006).

22. P. Montuori, S. Aurino, A. Nardone, T. Cirillo, M. Triassi, Environ. Sci. Pollut. Res. Int., 22, 8629, (2015).

23. R. Ahmad, P.N. Nelson, R. S. Kookana, J. Soil Sci. 57, 883, (2006).

24. L. Nemeth-kunda, G. Fûleky, G. Morovjan, P. Csokam, Chemosphere. 48 $545,(2002)$.

25. M. C. Fernández, L. Cox,M. C. Hermosin, J. Cornejo, Pest. Manag. Sci. 59, $545,(2003)$.

26. D.P. Oliver, R. S. Kookana, B. Quintana, J. Agric. Food Chem. 53, 6420, (2005) 
27. A. Sadzawka, M. A. Carrasco, R. Grez, M. L. Mora, H. Flores, A. Neuman, Métodos de Análisis de Suelos. Instituto de Investigaciones Agropecuarias (INIA). Serie Actas INIA 34, 59, 2006.

28. Servicio agrícola y ganadero de Chile (2012). Informe de ventas de plaguicidas de uso agrícola en Chile, año 2012. http://www.sag.cl/sites/default/files/declaracion_de_venta_de_plaguicidas_ ano_2012.pdf

29. Feng-Chin Wu, Ru-Ling Tseng, Ruey-Shin Juang . Chemical Engineering Journal. 150, 366, (2009).

30. OECD. Guidelines for testing of chemicals, Section 1 (106):AdsorptionDesorption using batch equilibrium method in soils. Environmental Health and Safety Division, Organisation for Economic Co-operation and Development (OECD), Environment. Directorate, Paris, France. 2000

31. X. Chen, Information 6, 14, (2015).

32. M. R. Shariff, International Journal of Engineering Research and Development 1, 55, (2012).

33. K. S. Ahmad, N. Rashid, M. F. Nazar, S. Tazaiyen, Journal of the Chemical Society of Pakistan 34-35, 1017, (2014).

34. I. Langmuir, J. Am. Chem. Soc. 38, 2221-2295 (1916).

35. A. O. Dada, A. P. Olalekan, A. M. Olatunya, O. Dada, Journal of Applied Chemistry. 3, 38, (2012).

36. J. Porta, M. Lopez - Acevedo, R. Porch, Edafología: uso y protección de suelos. 3ed. 272, 2014.

37. Y. Liu, Z. Xu, X. Wu, W. Gui, G. Zhu., Journal of Hazardous Materials. 178, 462, (2010).

38. D. Pal, S. K. Maiti, Environ Sci Pollut Res Int, 25, 12464, (2018).

39. F. Sadegh-Zadeh, S. A. Wahid, D. Omar, R. B. Othman, B. J. Seh-Bardan, Soil and sediment contamination, 20, 387, (2011).

40. H. J. Turin, R. S. Bowman, Journal of environmental quality, 26, 1282-1287 (1997).

41. S. D. Nelson, W. J. Farmer, J. Letey, C. F. Williams, Journal of environmental quality, 29, 1856-1862 (2000).

42. B. Von Oepen, B. W. Kördel, W. Klein, Chemosphere 22, 285-304 (1991).

43. C. H. Giles, T. H. MacEwan, S. N. Nakhwa, D. Smith, Journal of the Chemical Society. 3, 3973-3993 (1960).

44. J. P. Aguer, L. Cox, C. Richard, M. C. Hermosin, J. Cornejo, Journal of environmental science and health part B, 35, 725-738 (2000).
45. C. Dolaptsoglo, D. G. Karpouzas, U. Menkissoglu-Spiroudi, L. Eleftherohorinos, E. A. Voudrias, Journal of environmental quality. 36, 1793-1802 (2007).

46. F. A. Vega, Spanish journal of soil Sciencie. 1, 20-37 (2011).

47. A. F. Chamorro, R. D. Sanchez, Revista de Ciencias. 16, 145-160 (2012).

48. H.M.F. Freundlich, J. Phys. Chem. 57, 385-471 (1906).

49. Y. Long You, X. Wu, N. Shao, H. Fang, H. Zhan, J. Quan Yu, Environ. Pollut. 141:428-433 (2005).

50. O. P. Bansal. Journal of Applied Sciences and Environmental Management 14, 155-158 (2010).

51. E. H. Pérez, C. A. Arboleda, Suelos Ecuatoriales, 46, 59-66 (2016).

52. S. Gebremariam, M. Beutel, D. Yonge, M. Flury, J. Harsh, Rev Environ Contam Toxicol. 215, 123-75 (2012).

53. B. Gevao, K.T. Semple, K. C. Jones K.C. 2000. Environmental Pollution. 108, 3-14 (2000).

54. J. Cornejo, R. Celis, I. Pavlovic, M. A. Ulibarri. A review. Clay Minerals. 43, 155-175 (2007).

55. V. C. Farmer, M. M. Mortland., Journal of the Chemical Society A. 3, $344-$ 351 (1966).

56. G. Lagaly, Applied Clay Science, 18, 205 - 209 (2001).

57. J. J. Hasset, W. L. Banwart. The sorption of nonpolar organics by soils and sediments. En: Shawhney, B. L. y Brown, K. (Eds.), Reaction and movement of organic chemicals in soils. 31-44, 1989.

58. W. C. Koskinen, S. S. Harper. The retention process: mechanisms. En: Cheng, H. H. (Ed.), Pesticides in the soil environment: Processes, Impacts, and Modeling. Soil Science Society of America, Inc. Madison, Wisconsin 51-78, 1990.

59. C. T. Chiou. Partition and adsorption of organic contaminants in environmental systems. John Wiley and Sons. Hoboken, New Jersey. 150168. 2002

60. P. Sollins, P. Homann, B. A. Caldwell, Geoderma. 74, 65-105 (1996).

61. X. Ma, X. W. J. Bruckard, R. Holmes, Instituto J. Miner. 93, 54-58 (2009).

62. M. R. Seger, G. E. Maciel, Environ. Sci.Technol. 40, 791-796 (2006).

63. A. Kausar, M. ,Iqbal, A. Javed, K. Aftab, Z. Nazli, H. Bhatti, S. Nouren, $A$ review. Journal of Molecular Liquids. 256, 395-407 (2017).

64. S. Rihs, A. Gontier, E. Lascar, A. Biehler, M. P. Turpault, Applied Clay Science. 147: 128-136 (2017). 